\title{
EL SUEÑO DE CARLOMAGNO Y LOS DESTINATARIOS DE LA EPISTOLA LEONIS
}

\author{
Por \\ BOROBÓ
}

Con la lembranza de D. Xesús y D. Paulino

\section{RESUMEN}

En este trabajo se estudia el episodio de la aparición del apóstol Santiago a Carlomagno, contenido en el libro IV del Codex Calixtinus. El anacronismo de este hecho es justificado con la denominada Epistola Leonis (contenida en el libro III del Codex), probablemente del siglo XI, que es una narración atribuida a un papa León y dirigida a los reyes de Francos, Romanos, Godos y Vándalos, que habían reinado tres siglos antes que Carlomagno. A través de esta Epistola de ficción el Emperador tendría noticia de la existencia del sepulcro del Apóstol en los confines de Europa con anterioridad a su invención en el año 818.

\section{PALABRAS CLAVE}

Sepulcro de Santiago, Santiago de Compostela, Codex Calixtinus, Carlomagno.

«CUADERNOS DE ESTUDIOS GALLEGOS», Tomo L, Fascículo 116, Santiago 2003. 


\begin{abstract}
In this work there is studied the episode of the appearance of the apostle Santiago to Charlemagne contained in the book IV of the Codex Calixtinus. The anachronism of this fact is justified with the Epistola Leonis (contained in the book III of the Codex), probably of the century XI, which is a history attributed to a pope León and directed the kings of Francs, Romans, Goth and Vandal, that had reigned three centuries before that Charlemagne. Across this Epistola of fiction the Emperor would have news of the existence of the sepulcher of the Apostle in Europa's limits before his invention in the year 818 .
\end{abstract}

\title{
KEYWORDS
}

Sepulcher of Santiago, Santiago de Compostela, Codex Calixtinus, Charlemagne.

\section{EL SUEÑO DE CARLOMAGNO}

Al concluir mi monografía acerca de La traslación aérea de Santiago Apóstol, publicada en el anterior número de Cuadernos de Estudios Gallegos, me referí al misterioso período que atrevidamente titulé Burato negro na historia de Galicia. «Acaso en este agujero negro -decía- haya quedado oculto el misterio que encierra la Tumba compostelana y su temprano anuncio en la Epistola Leonis. Tratar de desentrañarlo, en lo posible, continuará siendo mi diversión histórica».

Lo fue, efectivamente, a lo largo de mis vetustos anacos, que al hilo de un multiforme y variopinto novelo, siguieron apareciendo en la prensa de la Galicia meridional; así como en varios artículos publicados en el pliego semanal que bajo el rubro de Correo do 93, editaba el Consorcio de Santiago. Y entre todo ese material que fui acumulando en esos y otros escritos, seleccioné y compuse el actual ensayo, que comienza -como el libro IV del Codex Calixtinus ${ }^{1}$, atribuido a la fantástica imaginación del Arzobispo Turpin- por el relato del sueño de Carlomagno.

«CUADERNOS DE ESTUDIOS GALLEGOS», Tomo L, Fascículo 116, Santiago 2003. 
Según la maravillosa narración del pseudo Arzobispo, «un caballero de apariencia espléndida y mucho más hermosa de lo que decirse puede, se le apareció en un sueño durante la noche» al Imperante de la barba florida, diciéndole:

«- ¿Qué haces, hijo mío?».

A lo cual, el rey de los francos, retrucó así, al modo que ahora se da en apodar gallego.

«- ¿Quién eres, señor?

»- Yo soy -respondió el apuesto caballero- Santiago Apóstol, discípulo de Cristo, hijo de Zebedeo, hermano de Juan Evangelista, a quien con su inefable gracia se dignó elegir el Señor, junto al mar de Galilea, para predicar a los pueblos; al que mató por la espada el rey Herodes, y cuyo cuerpo descansa ignorado en Galicia; todavía vergonzosamente oprimida por los sarracenos».

Carlomagno se había dormido pensando en el camino de estrellas que veía por las noches, y que se extendía desde el Mar de Frisia hasta Galicia; o sea, en donde precisamente se ocultaba, desconocido, el cuerpo de Santiago. Y en aquel sueño, que se repitió dos veces más, le resolvió el Apóstol al futuro Emperador la astronómica incógnita: conducía hasta el territorio de su propia tumba que se hallaba en poder de los sarracenos. Y Carlomagno debía ir con un gran ejército «a liberar mi camino y mi tierra», le indicaba el Hijo del Trueno.

Luego el Arzobispo Turpin escribe la gran patraña, fuente de los cantares del ciclo carolingio, que tanta trascendencia tuvo en la literatura francesa, sobre la peregrinación de Carlomagno a Santiago, llegando a Padrón donde «clavó una lanza en el mar».

Ocurriría este legendario episodio más bien en Rianxo; quizá en la playa de Tanxil, o mejor todavía en la de las Conchas, dado que Padrón no es puerto de mar. Sin embargo el arciprestazgo de Iría Flavia y la tierra padronesa, o de Iría, se bañan en la Ría de Arosa, merced a las márineras feligresías rianxeiras. Y después de ello, el Imperante, conquistaría fabulosamente toda España.

«CUADERNOS DE ESTUDIOS GALLEGOS», Tomo L, Fascículo 116, Santiago 2003. 
La verdad histórica y las contradicciones cronológicas no impidieron al afrancesado cabildo medieval compostelano dar como verídicas estas fantásticas hazañas de Carlomagno. Incluso se adelanta la fecha del descubrimiento de la Tumba, para que éste pudiese ser conocido por el Emperador, antes de morir el 28 de enero de 814.

Mas, el preclaro y joven historiador Fernando López Alsina puntualizó lo que luego yo divulgué en el siguiente artículo que vio la luz en el Correo do 93:

\section{«O BISPO KINDULFUS RETARDA VARIOS ANOS A INVEN- CIÓN DE SANTIAGO}

Ainda Chamoso Lamas, na súa aportación á colectiva obra sobre $L a$ Catedral de Santiago de Compostela ${ }^{2}$, dí que "fue en el año 813 o el 818 , nos inclinamos por la primera fecha, cuando el Obispo de Iría Flavia, Teodomiro, examina en el lugar denominado Arca Marmórica una tumba, que por varios vestigios que contenía, reconoció como la del Apóstol Santiago, Jacobo Boenerges, hijo del Zebedeo y de Salomé".

Podería así coincidir isa primeira data, pola que se inclinaba Manuel Chamoso, cos derradeiros días do emperador Carlomagno, morto no mes de xaneiro de 814. Estaría de ese modo conforme ca data que pon o Chronicon Iriense ${ }^{3}$, escrito polo ano 1080, e xa no século XII a Historia Compostelana $a^{4}$ O cal parecía "dar crédito a creencias populares que atribuían a Carlomagno la liberación del sepulcro jacobeo, en contra de la realidad histórica", como señala López Alsina.

Pois o cronista iriense e máis os historiadores composteláns esquenceran, sin que chegaran a transcurrir tres séculos, que naquel año 813 e durante o lustro posterior, inda rexía na diócesis de Iría o bispo Quendulfo, e habería que esperar, históricamente, a que Teodomiro encetase seu episcopado pra que ocurrira a Invención do sepulcro do Apóstol.

Despertóu miña curiosidad sobre esta polémica data, o mencionado historiador Fernando López Alsina, no seu libro acerca de La ciudad de Santiago de Compostela en la Alta Edad Media ${ }^{5}$, composto tras o acopio e compulsa de 765 escrituras anteriores ao ano 1151, topadas nos archivos de vinteoito institucións santiaguesas. De ahí que constituíu unha fonte inagotable de rectificacións e suxerencias a 
propósito da prehistoria de Compostela, e que veu a enriquecer extraordinariamente o acervo das investigacións xacobeas.

No que se refire a esta precisión cronolóxica, fundamental para a historia da ciudad de Santiago, López Alsina anota que o Bispo Quendulfo "el 16 de noviembre del 812 suscribe en la escritura fundacional de la iglesia de Oviedo y el 1 de septiembre de 818 confirma una escritura en Tumbos de Sobrado, I, no 43, pp. 75-77'. Estaba vivo Quendulfo, polo tanto, a fines do 818; ou sexa un lustro despóis da data atribuida ao descubrimento da Tumba feito polo seu sucesor Teodomiro.

Xa López Ferreiro citara na sua magna Historia de la Santa A.M. Iglesia de Santiago de Compostela, non soio un senón dous documentos ovetenses do 812, suscritos polo bispo Quindulfus, outra escritura anterior de Samos, firmada por Quendulfus, e ademáis o trascendental documento de Sobrado. Mais, o inxel historiador, para soster a posibilidad de que Carlomagno chegara a ter coñecemento da Invención do Corpo de Santiago o Maior, mantuvo a data do 813, xustificandoa de esta peregrina maneira: "Contra esto podrá alegarse una Escritura del Tumbo de Sobrado, datada el $1^{\circ}$ de septiembre de 818 , en la cual se cita como testigo a Kindulfus, Obispo de Iría. Según esto, no habiendo podido ser Teodomiro Obispo de Iría antes de esa fecha, después de esta fecha es forzoso colocar el descubrimiento del cuerpo del Apóstol. Mas, si bien se mira, la cita que allí se hace de Quendulfo como testigo, no es para el otorgamiento de la escritura, sino para la entrega de unos bienes, que debió haberse hecho algunos años antes".

Capciosa deducción a feita polo sabio coengo, pois contradicese co texto do mesmo documento que López Ferreiro reproduce como Apéndice $\mathrm{n}^{\circ} \mathrm{I}$ do Tomo II da súa grande Historia. Onde se ve, ao final da escritura, que Quendulfo non é un simple testigo, senón quen a confirma, poñendo: Sub Xpisti nomine Kindulfus dei gratia episcopus confirmo».

\section{A TOMAR LAS AGUAS}

Si la fecha del 818 parece la más convincente para datar el descubrimiento, por el obispo Teodomiro, de la Tumba del Apóstol, ello ocurriría 
cuarenta años justo después de la Rota de Roncesvalles, fechada en el 778 , que es el hecho histórico que con mayor precisión y dramática fantasía se relata en la Crónica del Arzobispo Turpin ${ }^{1}$.

Allí perdió Carlomagno (en la retirada pirenaica de su ejército, tras el frustrado intento de arrebatar Zaragoza a los musulmanes) la flor de sus caballeros; singularmente a su sobrino Roldán, el héroe de la Chanson de Roland, máximo poema épico francés.

Contaba entonces el rey de los francos treinta y seis estíos; luego, al ser coronado emperador en Roma, por el Papa León III, el día de Navidad del redondo año 800 , frisaba en los cincuenta y ocho otoños. Al morir, en el 814, sumaría setenta y dos inviernos. ¿Cuántos años tendría en el maravilloso momento en el que se le apareció, tal como si fuese un apuesto caballero, Santiago Apóstol, hijo de Zebedeo, animándole a liberar su camino y su tierra de Galicia?

Murió Carlomagno sin que hubiese podido enterarse siquiera de la Invención de la Tumba de Santiago, por vía diplomática. Pues con la cronología difícilmente cabe hacer milagros, ya que se trataba de una ciencia auxiliar de la Historia, rigurosa e implacable.

Aunque las comunicaciones de Carlomagno con el Rey de Asturias y Galicia, Alfonso II el Casto, eran fluidas y rápidas; si se descuenta el atraso natural en las estructuras viarias de la Alta Edad Media.

Así, pudo Carlomagno firmar un tratado de alianza con quien los Anales carolingios denominaban todavía, hacia 794 , principes Galliciarum. Pero sólo transcurrieron tres años hasta el día en que el rey de los francos recibió personalmente, en Herrstal, al embajador de Alfonso II, a quien los cronistas franceses llaman ya Rex Galleciae et Asturias.

Este embajador del rey de Galicia y Asturias era un clérigo ovetense, Basílico de nombre. Habría de volver, en el invierno de 798, a la corte del monarca franco; al cual aún le faltaba un par de años para que Basílico pudiese tratarle de Emperador de Occidente ${ }^{7}$.

Quizá el embajador Basílico aprovechase la ocasión para tomar las aguas medicinales que dieron nombre a la capital del imperio carolingio en los distintos idiomas europeos. Pues si bien Aquisgram es su clásico nombre español, se llama Aix-la-Chapelle en francés y Aachen en alemán. Todos estos topónimos recuerdan que Carlomagno empezó yendo allí a beber sus aguas minerales. 


\section{LA EDAD DE CARLOMAGNO}

Me preguntaba en el anaco precedente acerca de la edad que tendría Carlomagno cuando se le apareció en sueños el Apóstol Santiago, indicándole que siguiese el camino de estrellas que conducía a Galicia, para liberarla de los sarracenos y visitar, decía, «mi basílica y sarcófago».

Tras meditarlo durante una noche entera, deduje que fue sin duda antes de emprender el rey de los francos la infortunada expedición militar que tan trágicamente acabó en Roncesvalles, yendo ya de retirada hacia su reino. Antes pues, del 778, cuando aún faltaban más de cuatro decenios para que se iniciase la edificación del Burje Libredón, o sea del burgo primitivo de la futura Compostela ${ }^{5}$.

Sí es así, el fabuloso Arzobispo Turpin, en su Libro -cuarto del Codex Calixtinus-, al relatar el sueño de Carlomagno, hace que el Apóstol despierte demasiado pronto la ilusión del futuro Imperante, al invitarle a visitar su basílica y su sarcófago, puesto que el sepulcro no se descubriría (siguiendo a López Alsina) con anterioridad al 818, y dado que la primera basílica santiaguesa, la de Alfonso III el Magno, fue consagrada el 6 de mayo de $899^{6}$.

Casi un siglo después de ser Carlomagno coronado emperador en Roma. Precisiones cronológicas que tendrían sin cuidado al pseudo Arzobispo Turpin, al pseudo Papa Calixto y a cuantos más redactaron el Codex Calixtinus; adulterando insignes textos, acomodados a sus fines jacobeos y apañando sermones y milagros, junto con la escritura de las pasmosas guías medievales del Camino y de la Ciudad y la Catedral de Santiago, que a Aymerico Picaud cabe atribuir ${ }^{8}$.

Pues conforme a la mágica interpretación de la Epistola Leonis, imaginada por Filgueira Valverde, en su precioso Libro de Santiago, la primera estrella del camino celeste observado por Carlomagno -la Galaxia, o Vía Láctea- sería la propia figura de Santiago el Mayor: «Estrella más que rayo el mismo, hijo del Trueno». Como imaginara el finado presidente del Consejo de Cultura Gallega y director del Instituto P. Sarmiento9.

En cuanto al conocimiento que el Emperador hubiera podido tener de la existencia de la Tumba de Santiago, con bastante anterioridad a la Invención de Teodomiro, acaso Carlomagno se haya enterado de ello a través del arquetipo perdido de la Epístola del Papa León, enviada a los

«CUADERNOS DE ESTUDIOS GALLEGOS», Tomo L, Fascículo 116, Santiago 2003. 
reyes francos, vándalos, godos y romanos, los cuales había reinado tres siglos antes que el Imperante de la barba florida.

Y como en la misteriosa Epístola se afirmaba que había ascendido Santiago Apóstol hasta el Sol (tal como informé en mi ensayo anterior), no parece excesivamente exagerado que Carlomagno le viese aparecer en sueños, acaso procedente de los espacios siderales.

\section{O ANUNCIO DOS REIS DE OCCIDENTE DA TRANSLATIO DO APÓSTOL}

«A pasmosa Epístola chamada do Papa León -escribiamos tamén no Correo del 93-, na que se anuncia a traslación do Corpo do Apóstol, polo mar e polo aire, e a súa inhumación sub arcis marmoricis, está dirixida por Leo episcopus aos regibus francorum, et vandalorum, gotorum et romanorum; como monarcas representativos da Cristiandad occidental nun momento histórico no que se denominóu romano ao rei ostrogodo Teodorico.

Quen máis fondamente a estudióu ata agora -o profesor López Alsinaexplica que "la epístola carece de datación expresa, pero los cuatro destinatarios principales de la misma, los reyes de las monarquías germánicas más importantes del occidente bárbaro desde una perspectiva histórica posterior, nos sitúan directamente en un ámbito cronológico comprendido entre los años 476 y 535. El autor se presenta como Patriarca de Jerusalén, ciudad en la que se celebraba un sínodo cuando regresaron los cuatro discípulos (del Apóstol) y desde donde acto seguido dirige la carta". "Los objetivos fundamentales que se persiguen con la redacción del texto -añade Fernando López Alsina- no son otros que comunicar a los cuatro reyes el hecho de la translatio, notificarles la existencia de un culto sepulcral circunscrito aún a las gentes del reino suevo y garantizarles la autenticidad de la presencia sepulcral del Apóstol en la Península, para que también sus respectivos pueblos puedan incorporarse activamente al culto sepulcral".

Semellaría explícita nesta longa cita a datación na época sueva -por este historiador tan xustamente calificado de perfeccionista-, da Epistola, mellor chamada, do Patriarca León de Jerusalén, si en outras páxinas da súa esclarecedora obra (La ciudad de Santiago de Compostela en la Alta 
Edad Media) non mostrara a máxima cautela, propia dun investigador histórico da súa categoría, datando a Epistola tres séculos despóis, no mismo tempo do descubrimento da Tumba de Santiago.

Así escribe: "La colación y el análisis de estos tres textos (os máis antigos da Epístola) nos inclinan a suponer la existencia de un arquetipo perdido de la primera mitad del siglo IX, fuente común de las tres redacciones y punto de origen y base de partida para todas las sucesivas transformaciones y enriquecimientos posteriores que acabarán dando lugar a otros epístolas literariamente más desarrolladas, que serán atribuidas a un Papa León".

Máis, o que non é lícito a un historiador cabal e profesional, pódeselle tolerar a un ensaista, ou diletante da historia. Pois no ensaio cabe, como sostiña Marañón, dar á argumentación sin a proba; e polo tanto reemplazar a carencia de documentos co exercicio da intuición histórica máis destemida.

E neste caso abonda con dar validez histórica ao que López Alsina somentes expón coma unha situación que lle suxere o texto ideal de aquel arquetipo: "Los siete discípulos se presentan en Galicia en plena época de dominación sueva a finales del siglo $\mathrm{V}$, horizonte histórico de tiempo real que, en el fondo, se nos propone para la traslatio efectiva a Galicia"s.

Pois ben, ese tempo cadra exactamente -e volve a tomar a palabra iste afoutado ensaista - co burato negro da historia do noso país. Xa que dende o ano 468 no que acima o Cronicón de Idacio, deica o 559 cando o Biclarense enceta súa historia, nin siquera se sabe os nomes dos monarcas suevos, nin canto sucedéu aquí ademáis nesa linguísima etapa. Coma resaltéi no meu traballo adrede de Os dous San Martiño ${ }^{10}$.

E pudo vir moi ben cara o sol, polos aires, o Fillo do Trono, entre aqueles anos 476 a 535 -comprendidos no tempo do burato negro-sin que ningún hipotético cronista de ese misterioso período dera conta do prodixioso viaxe que notificóu entón o Patriarca León aos reis de Occidente».

\section{LOS SECUACES DEL PADRECITO ATILA}

Carlomagno reunía en su testa las coronas de casi todos aquellos regibus francorum, et vandalorum, gotorum et romanorum, a los que fue dirigida la arcana Epistola Leonis, atribuida por el profesor López Alsina a un Patriarca León de Jerusalén, en vez de a un Papa León de Roma ${ }^{5}$. 
El misterio de la Epistola se acentúa al considerar que tales reyes representativos de la Cristiandad Occidental, reinaban en un momento histórico en el cual se titulaba romano el monarca ostrogodo Teodorico. Situándose cronológicamente entre los años 476 y 535, mientras los suevos dominaban Galicia. O sea tres siglos antes que el imperio de Carlomagno.

Ese momento histórico estaba, en cierto modo, caracterizado inicialmente por el papel que jugaron entonces los vástagos de los principales consejeros del rey huno Atila, «el azote de Dios». Pues en la corte trashumante de Atila (diminutivo gótico que significaba «padrecito»; algo así, como se denominaría quince siglos después al «padrecito Stalin») figuraban griegos y romanos, godos y escitas.

El primer ministro de este pequeño «padrecito» (ya que Atila, como tantos grandes hombres, era de muy baja estatura) fue el griego Orestes, padre de Rómulo Augústulo, quien habría de ser el último de los emperadores romanos de Occidente. Otros secuaces de Atila fueron el escita Edecón, que sería el progenitor de Odoacro, y el ostrogodo Teodomiro, padre del mencionado Teodorico.

Muerto el «azote de Dios» (en el 452), aquellos heterogéneos personajes recobraron su independencia y, ante todo, sus bárbaras ambiciones de poder. Así Orestes, convertido en magister militum del emperador Julio Nepote, se sublevó contra éste y tuvo la audacia de colocar la púrpura imperial (en el 475) a su hijo Rómulo Augústulo.

Pero al año siguiente el escita Odoacro, nuevo magister militum, puesto al frente de los mercenarios bárbaros mata a Orestes y encarcela a su hijo, el último emperador romano de Occidente; que llevaba, paradójicamente, el mismo nombre del primer rey de Roma. Esto ocurría el año 476 y vino a ser el hecho que marca el comienzo de la etapa histórica en que reinaron los destinatarios de la Epistola Leonis.

Odoacro se contentó con ser el efectivo rey de Italia, desdeñando la corona del Imperio Occidental. Tanto que envía, cuidadosamente empaquetadas, las insignias imperiales de Bizancio, al Emperador romano de Oriente, sin reclamar la investidura de ellas a su favor.

Tal gesto irritó a Zenón, el anciano emperador bizantino; quien encargó a Teodorico, el caudillo del nómada pueblo ostrogodo, la misión de liberar a Italia de su flamante rey y restablecer la autoridad imperial en Occidente.

Las innumerables carretas de la horda ostrogoda se pusieron en marcha. Atravesaron lentamente las tierras ahora de Bulgaria y las de Servia 
y Croacia (tan reciente y sangrientamente disputadas). Y en la primavera del 488, los ostrogodos cruzaron los Alpes ${ }^{11}$.

\section{EL FUROR OSTROGODO DE TEODORICO}

La marcha de los ostrogodos a través de las siempre conflictivas tierras balcánicas fue necesariamente lenta, dado que rara era la jornada en que no tenían que batirse con la población indígena que les hostilizaba. Pero al fin, cruzados los Alpes y tomado Trieste, la llanura de Venecia apareció a la vista de los feroces guerreros de Teodorico.

Odoacro, el escita que reinaba en Italia, les esperaba con sus tropas, en la otra orilla del Isorno. Teodorico arengó a sus ostrogodos, resaltándoles que si fuesen vencidos, sus mujeres y sus niños, que les acompañaban en las carretas de la horda por los interminables caminos de su constante nomadismo, serían vendidos en los mercados de esclavos: donde tanto se les apreciaba por lo rubio de su pelo y lo blanco de su piel. Si vencían, en cambio, los ostrogodos, la hermosa y fértil Italia sería suya, pues el emperador bizantino les había concedido legalmente su dominio.

Y Teodorico, al frente de sus jinetes, jugándose el todo por el todo, se lanzó al ataque. Tal fue su furia que Odoacro, aunque combatió valerosamente, tuvo que replegarse sobre el Adigio. Pronto se rehizo y un mes después (29-IX-489) entró en batalla cerca de Verona, siendo nuevamente derrotado por el rey ostrogodo, si bien pudo escapar y refugiarse en Rávena.

Desde allí Odoacro recompuso su ejército, haciéndole capaz de enfrentarse por tercera vez con Teodorico (11-VIII-490), al este de Milán; sufriendo el mismo resultado en el furioso combate. Otra vez tuvo que buscar Odoacro refugio tras las murallas de Rávena, donde resistió dos años y medio sin rendirse. Hasta que abrió sus puertas al negociar con Teodorico el reparto de Italia (25-III-493).

Veinte días después el rey ostrogodo, ya instalado en un palacio de Rávena, invitó a Odoacro a almorzar. Para lanzarse sobre él en cuanto entró en el refectorio y, tras insultarle furiosamente, le atravesó con su espada.

De esa forma, la autoridad de Teodorico, como legado del emperador de Oriente, se extendió por toda Italia, pero nunca pudo obtener de Bizancio 
que reconociera su legitimidad como emperador de Occidente. Lo que acaso hizo que gobernase pacíficamente durante treinta años, con la habilidad y la sabiduría política propias de un antiguo cónsul romano.

Así, restableció la grandeza del Senado, presidido por Símaco, y escogió entre los senadores a sus ministros, encabezados por Boecio, insigne pensador y yerno del presidente.

Tan pacífica convivencia entre los arrianos ostrogodos y los católicos romanos, se vio alterada por la cruel beatería de Justino, el nuevo emperador de Bizancio, que persiguió sañudamente a los correligionarios de Arrio y de Teodorico. Respondiendo a esa persecución, el rey de los ostrogodos prendió al Papa Juan I y le embarcó para Constantinopla; haciéndole portador de su virulento mensaje al emperador Justino; quien se prosternó ante el Pontífice y se hizo coronar por él.

Llovía sobre mojado, pues los bizantinos disponían de espías en Roma que alentaban la conspiración de los senadores católicos contra el arriano Teodorico. Lo cual desataría el terrible furor del rey ostrogodo ${ }^{11}$.

\section{SIN CONTAR LOS ANTIPAPAS}

Da la casualidad de que ninguno de los papas que pontificaron durante el período histórico en que reinaron los monarcas destinatarios de la llamada Epistola del Papa León, llevó este repetido nombre que habrían de usar, hasta hoy trece vicarios de Cristo.

Puesto que desde el final del Imperio Romano de Occidente (476), momento en que empieza la época en cuestión - o sea la de los regibus francorum et vandalorum, gotorum et romanorum-, hasta la total extinción de los vándalos por los bizantinos (534), en que ella termina, ningún santo padre aparece que se llamara León en la inmensa lista de los pontífices romanos.

A pesar de que -sin contar los antipapas- hubo nada menos que siete papas que fueron coetáneos de Teodorico, durante el tiempo que el rey ostrogodo dominó Roma. A saber: S. Simplicio, S. Félix III, S. Gelasio, Anastasio II, S. Símaco, S. Hormidas y S. Juan I. Y tres más posteriormente a Teodorico: S. Félix IV, S. Bonifacio II y Juan II.

El rey ostrogodo y la posible víctima de su furia, el Papa S. Juan I, murieron en el mismo año (526). Ya conté que el Emperador de Oriente, 
Justino, se había prosternado ante este Pontífice, cuando llegó a Constantinopla, y se hizo coronar por él. Lo cual fue considerado por Teodorico como una provocación, y al regresar Juan I a Roma ordenó encarcelarlo. Y, claro está, se atribuyó la muerte del Papa a los malos tratos recibidos en prisión.

Teodorico contaba ya setenta y tres años y sufría -según deducen los médicos de ahora- un cáncer de estómago que agriaba su carácter. Su hija Amalasunta, verdaderamente espantada, trataba en vano de calmar el furor del terrible ostrogodo.

Había mandado ejecutar a su antiguo ministro, Anicio Manlio Torquato Severino Boecio, por suponer que estaba complicado en las conspiraciones de los católicos romanos y los bizantinos contra él. Boecio, durante los días que pasó en la cárcel esperando la ejecución de la pena capital, se entretuvo escribiendo De consolatione philosophiae; un libro donde el antiguo cónsul, senador y ministro dialoga serenamente con la matrona Filosofía. Por ello, luego Dante le instaló en el Paraíso.

Pero el gran Teodorico, que en el transcurso de treinta años había gobernado Italia en paz, como legado imperial, se había trocado en sus últimos meses, quizá a causa de su horrible dolencia, en un tirano implacable, singularmente para los católicos. En el mismo mes de su muerte (30-VIII-526) aún tuvo la ocurrencia de decretar la clausura de todos los templos de la Iglesia Católica y prohibir su culto fuera de ellos.

Así acabó la vida del monarca que cubrió, en el tiempo y en el espacio, el mayor ámbito de ese período marcado por los destinatarios de la Epistola Leonis. Pues no cabe olvidar que Teodorico ejerció también una especie de soberanía sobre el reino visigodo de las Galias y de España, desde la muerte de su yerno Alarico II. Dado que, como tutor de su nieto Amalarico, desempeñó la regencia de este reino durante quince años: desde el año 511 hasta su fallecimiento ${ }^{11}$.

\section{LOS ABUELOS Y EL SUEGRO DE AMALARICO}

$\mathrm{Al}$ iniciarse el período histórico marcado por la existencia de los destinatarios de la Epistola Leonis, el reino visigodo no era propiamente un estado español, sino galo-hispano, tanto que su corte en vez de hallarse en España, residía en la Galia Meridional, bien fuese en Tolosa, Burdeos o 
Arlés. Desde allí el gran rey Eurico trataba de extender el dominio visigodo por el resto de las Galias y de la Península Ibérica, durante los años posteriores al fin del Imperio Romano de Occidente y hasta su propia muerte. Es decir, desde el 476 al 484.

La preeminencia del visigodo Eurico entre los pueblos germanos fue bien manifiesta mientras reinó. Y este papel hegemónico lo habría de asumir más tarde el ostrogodo Teodorico, desde que en el decenio siguiente impuso su autoridad en Italia. Para consolidarla, realiza una política de alianzas matrimoniales con los demás jefes bárbaros. Se casa él mismo con una hermana de Clodoveo, el pujante rey de los francos, enviando a su vez princesas ostrogodas para casarse con jefes visigodos, vándalos y burgundios. Entre ellas, una de sus hijas, que enlaza matrimonialmente con el rey visigodo Alarico II, hijo y sucesor del gran Eurico.

Reinó Alarico II sólo trece años (484-507), pues halló la muerte, en la batalla de Vouillé, cerca de Poitiers, en la que los visigodos fueron derrotados por los francos que acaudillaba Clodoveo. Dejaba el heroico rey un hijo legítimo, Amalarico, nieto de Teodorico, que contaba entonces únicamente un lustro.

Por ello, los nobles visigodos eligen rey a Gesaleico (507-511), hijo natural del finado monarca, quien no puede contener el empuje creciente de los francos, que van ocupando las principales ciudades hasta entonces en poder los godos: Burdeos, Angulema, Tolosa, Narbona... Hasta el punto que Gesaleico tiene que refugiarse en Barcelona. A fines de 510, el dominio franco del gran rey Clodoveo se extendía desde las montañas de Sajonia hasta las costas normandas y desde la desembocadura del Rhin hasta los Pirineos, anticipándose así en tres siglos a la concepción imperial de Carlomagno. Sólo le restaba atacar y vencer a su cuñado Teodorico para poderse ceñir en Roma la corona de Emperador de Occidente. Pero un día de diciembre de 511 amaneció con fiebre, sin que esta le inquietase. Al empeorar, acudió a su cabecera San Remigio, el obispo de Reims que había convertido al terrible rey salio al cristianismo. Una semana después murió. Posiblemente de un ataque de apendicitis...

Desaparecida la amenaza que suponía la idea imperial de Clodoveo, el rey Teodorico pasa a la ofensiva, en apoyo de las pretensiones de su nieto Amalarico a la corona visigoda. Las tropas ostrogodas levantan el cerco de Arles y Carcasona y recuperan Narbona. Luego marchan a Barcelona, poniendo en fuga al rey Gesaleico, hasta que lo capturan y acaban con él. 
Allí los ostrogodos ponen en el trono a Amalarico (511-531), y se apoderan del tesoro real de los visigodos, constituido principalmente por las presas más valiosas que habían depredado en el saco de Roma (23VIII-410), capitaneados por su gran rey Alarico I. Destacaba entre ellas una alhaja salomónica, que quizá fuese la misma célebre mesa de Salomón, de la cual se apoderarían dos siglos después los árabes, al conquistar Toledo, mandados por Tarik ${ }^{12}$.

\section{LOS DESTINATARIOS DE LA EPÍSTOLA LEONIS}

La regencia que Teodorico, el rey de los ostrogodos, ejerció durante la minoridad de su nieto Amalarico, el rey de los visigodos, se prolongó a lo largo de dieciséis años (515-526) y sólo finalizó con la muerte del viejo monarca germano... y romano. En ese tiempo, Teodorico rigió, desde Roma, a los visigodos, mediante diversos nobles ostrogodos que le representaban. Así supo conservar lo que quedaba del antiguo reino de Eurico en las Galias y en España.

Al morir su abuelo, contaba ya Amalarico veinticinco años y comenzó su personal reinado (526-531) perdiendo Arles con toda la Provenza, ganada por los francos. Claudica ante éstos y se casa con Clotilde, hija del ya finado Clodoveo; a la cual, al poco maltrata, acaso por ser católica, mientras él era arriano.

Entonces el hermano de ella, Khilderberto, que había heredado el reino de la Isla de Francia, en el reparto de los territorios del gran Clodoveo, venga a Clotilde, derrotando a su cuñado en una batalla dada cerca de Narbona. Huye Amalarico (igual que lo hiciera su hermanastro Gesaleico en ocasión precedente) a Barcelona, y allí le apuñala Besson, uno de los francos que le perseguían.

Termina así la poderosa dinastía de los Balthos que rigió casi hereditariamente a los visigodos y se restablece en puridad el principio electivo, al ser elegido rey Teudis (532-548), uno de los nobles ostrogodos que había enviado Teodorico para gobernarles en su nombre. El reinado de Teudis rebasó ampliamente el período histórico correspondiente a la Epistola Leonis (476-534) que concluye con la destrucción de los vándalos por los bizantinos ${ }^{12}$.

«CUADERNOS DE ESTUDIOS GALLEGOS», Tomo L, Fascículo 116, Santiago 2003. 
Se estaba, pues, fuera del período marcado por los destinatarios de la Epístola Leonis y ya finalizaba también el agujero negro de la Galicia sueva. Pues así como se ha podido seguir el hilo -en este ensayo- de los monarcas que reinaron en aquella especie de Comunidad económica -0 política- europea, que formaron tales naciones germánicas, desde el 476 al 535, un silencio absoluto reina en la Historia respecto al nombre y los hechos de los reyes suevos que habrán dominado durante un ámbito cronológico treinta años más largo. Pues el agujero negro, que así venimos denominando ${ }^{10}$, se extiende desde el 468 al 559; por tanto casi un siglo de enorme oscuridad en el que pudo pasar de todo. Incluso la traslación aérea del cuerpo del Apóstol Santiago...

\section{NOTAS}

${ }^{1}$ Liber Sancti Jacobi. Codex Calixtinus. Traducción por los Prof. A. Moralejo, C. Torres y J. Feo. Dirigida, prologada y anotada por el primero. C.S.I.C. Instituto Padre Sarmiento de Estudios Gallegos. Santiago de Compostela, 1951.

${ }^{2}$ CHAMOSO LAMAS, Manuel. «El Prerrománico», en La Catedral de Santiago de Compostela. Caja de Ahorros de Santiago, 1977.

${ }^{3}$ El Cronicón Iriense. Estudio preliminar, edición crítica y notas históricas por M.R. García Álvarez, en Memorial Histórico Español, 1963.

${ }^{4}$ Historia Compostelana. Edición de Emma Falque Rey. Akal. Clásicos latinos medievales. Madrid, 1994.

${ }^{5}$ LÓPEZ ALSINA, Fernando. La ciudad de Santiago de Compostela en la Alta Edad Media. Centro de Estudios Jacobeos, Santiago de Compostela, 1988.

${ }^{6}$ LÓPEZ FERREIRO, Antonio. Historia de la S.A.M. Iglesia de Santiago de Compostela. Tomo II, apéndice I. Imprenta del Seminario Conciliar Central. Santiago, 1899.

${ }^{7}$ CHOCHEYRAS, Jacques. Ensayo histórico sobre Santiago de Compostela. Pág. 121. Gedisa editorial. Barcelona, 1989.

${ }^{8}$ VÁZQUEZ DE PARGA, Luis; LACARRA, José Ma; URÍA RIU, Juan. Las peregrinaciones a Santiago de Compostela. Edición facsímil de la realizada por el C.S.I.C. en 1948. Gobierno de Navarra. Pamplona, 1992.

${ }^{9}$ FILGUEIRA VALVERDE, J.F. El libro de Santiago. Editora Nacional. Madrid, 1948.

${ }^{10}$ BOROBÓ (Raimundo García Domínguez). «Os dous San Martiño. O primeiro Patrón e o primeiro Apóstol de Galicia». Tomo XLVI, Fascículo III, de Cuadernos de Estudios Gallegos, 1999.

${ }^{11}$ SAINT-PHALlE, Alexandre de. De San Pablo a Mahoma: Atila, Clodoveo, Teodorico. Ediciones Castilla. Madrid, 1962.

${ }^{12}$ Historia de Espáña. Dirigida por R. Menéndez Pidal. Tomo III. Capítulos I-V. Espasa-Calpe, Madrid, 1940.

«CUADERNOS DE ESTUDIOS GALLEGOS», Tomo L, Fascículo 116, Santiago 2003. 